\title{
Perfil e Inserção Profissional do Licenciado em Computação no Brasil
}

\author{
Lilian Pereira da Silva Teixeira \\ Instituto Federal de Educação, Ciência e Tecnologia Baiano (IF Baiano) \\ Estrada da Igara, Km 04. Senhor do Bonfim, BA - Brasil \\ lilian.teixeiradifbaiano.edu.br
}

\begin{abstract}
The present article presents part of the results of a doctoral thesis whose main object of research was the professional development of graduates of Computer Science courses. In the article in question will be presented data that contribute to the understanding of the profile of the graduates and the degree of difficulty and also the potential of the professional insertion of the licenciado in Computing. The research methodology is based on the qualiquanti approach. The subjects were 60 graduates from the five regions of Brazil who answered an online questionnaire. It is concluded that the professional insertion of the graduates is satisfactory with indicators of potentialities, although the graduates negatively evaluate the professional insertion in the aspect of the non existence of a consolidated offer of discipline in the area of computation in Basic Education.
\end{abstract}

Resumo. O presente artigo apresenta parte dos resultados de uma tese de doutorado que teve como principal objeto de investigação o desenvolvimento profissional de egressos de cursos de Licenciatura em Computação. No artigo em questão apresentar-se-á dados que contribuem para a compreensão do perfil dos egressos e do grau de dificuldade e também as potencialidades da inserção profissional do licenciado em Computação. A metodologia da pesquisa pauta-se na abordagem quali-quanti. Os sujeitos participantes são 60 egressos das cinco regiões do Brasil que responderam a um questionário online. Conclui-se que a inserção profissional dos egressos é satisfatória com indicadores de potencialidades, embora os egressos avaliam de forma negativa a inserção profissional sob o aspecto da não existência de oferta consolidada de disciplina na área de computação na Educação Básica.

\section{INTRODUÇÃO}

Para contextualizar a oferta da Licenciatura em Computação (LC) ${ }^{1}$ no Brasil, a Sociedade Brasileira de Computação (SBC) apresenta em sua base de dados importantes índices estatísticos que revelam o crescimento na oferta da Licenciatura

\footnotetext{
${ }^{1}$ Ressalta-se que neste estudo optou-se por utilizar o termo Licenciatura em Computação para referir a todos os cursos de formação de professores para a área de computação, informática e tecnologias digitais da informação e comunicação. Essa opção se deu pelo fato do termo "Licenciatura em Computação" ser o termo predominante no censo 2016 dos cursos superiores, no censo promovido pelo INEP/MEC, com resultados publicados em 2017.
} 
VIII Congresso Brasileiro de Informática na Educação (CBIE 2019)

Anais do XXV Workshop de Informática na Escola (WIE 2019)

em Computação no Brasil, do período de 1997 a 2016, esses dados revelam que em 10 (dez) anos o número de cursos de LC no Brasil cresceu $296 \%$. Em 2006, havia 30 (trinta) cursos em todo o país, em 2016 esse número chegou a 86 (oitenta e seis) cursos.

Os cursos de LC atualmente estão mais concentrados na região Nordeste, onde se pode contabilizar um número de 26 (vinte e seis) cursos; em segundo lugar está a região Norte, na qual estão registrados 19 (dezenove) cursos existentes; em terceiro lugar encontra-se a região Centro-Oeste, que apresenta 16 (dezesseis) cursos de LC em atividade; em quarto lugar está a região Sul, com 15 (quinze) cursos, e em último lugar a região Sudeste que oferta apenas 13 (treze) cursos de Licenciatura em Computação.

Portanto, os dados apresentados têm a intencionalidade de contextualizar e justificar a necessidade urgente de se investigar os campos de atuação e as concepções desse profissional que é considerado ainda recente tanto para a área da docência quanto para a área da Computação.

Atualmente existem 89 (oitenta e nove) cursos de LC (Brasil, 2017) espalhados pelo Brasil que formam novos profissionais a cada ano, o que justifica ser de grande pertinência para o meio acadêmico um trabalho dessa natureza que apresenta uma devolutiva sobre como tem sido a inserção profissional desses novos educadores na área da Computação no contexto educacional, bem como o modo com o qual se delineia o seu perfil profissional.

A Licenciatura em Computação é um curso relativamente novo, possui um grupo de egressos que ainda está na fase inicial do ciclo de vida profissional. É válido ressaltar que há diretrizes que normatizam o curso de formação de professores para o ensino de Computação, nas quais indica-se que a atuação deste profissional poderá ocorrer desde a Educação Básica, trata-se da Resolução $n^{0}$ 05, de 16/11/2016, que estabelece Diretrizes Curriculares Nacionais para os Cursos de Graduação em Computação (DCN-DGCOM).

Porém, há uma questão importante a ser analisada no que se refere à inserção profissional do licenciado em Computação, trata-se da não obrigatoriedade do ensino de Computação na Educação Básica. Assim, questiona-se: - Como constituir-se-á a identidade profissional do professor de Computação visto que seu perfil profissiográfico apresenta a atuação na Educação Básica, mas não há espaço assegurado no currículo escolar para o ensino de Computação?

Conforme Santos e Hinterholz (2017), a Lei de Diretrizes e Bases da Educação Nacional (LDBEN), Lei de $\mathrm{n}^{\circ}$ 9394/1996, apresenta a área de formação tecnológica apenas como elemento transdisciplinar a partir do Ensino Fundamental. O Plano Nacional de Educação 2014-2024 no que se refere à área de Computação apresenta somente indicativos para maior informatização das escolas da Educação Básica, assim como propõe que se triplique a relação aluno/computador nas escolas.

Desse modo, pode-se perceber que não há amparo legal na educação brasileira que assegure o ensino de Computação desde a Educação Básica. Enfim, essa situação configura-se numa contradição no contexto de um país que cria e promove um curso de formação de professores para o ensino de Computação desde a Educação Básica, porém não assegura a inserção da Computação na estrutura curricular da Educação Básica.

Assim, no presente artigo busca-se como objetivo indicar dados e índices que apresentem o grau de dificuldade, bem como, potencialidades a respeito da inserção profissional dos egressos da Licenciatura em Computação. 
VIII Congresso Brasileiro de Informática na Educação (CBIE 2019)

Anais do XXV Workshop de Informática na Escola (WIE 2019)

\section{DESENVOLVIMENTO}

A metodologia adotada para a coleta dos dados amparou-se no método misto (qualiquanti), que permite a triangulação dos dados. A triangulação é amplamente defendida como "a combinação de metodologias no estudo do mesmo fenômeno" (Denzin, 1978, apud JICK, 1979, p. 602). A pesquisa quali-quanti permite a comparação de dados que foram colhidos por métodos ou ainda instrumentos diferentes. A triangulação pode acontecer de duas formas, através da combinação de métodos diferentes, ou ainda, através de técnicas diferentes dentro de um mesmo método.

Assim, optou-se por utilizar dois instrumentos principais para a recolha de dados: o questionário online semiaberto, o qual se constituiu como principal fonte de dados quantitativos, (embora também tenha se caracterizado como fonte qualitativa, pois existiram questões abertas, porém em menor proporção) e a entrevista semiestruturada, fonte principal de levantamento qualitativo. Justifica-se a escolha de tais instrumentos diante da necessidade de obter instrumentos que facilitassem o alcance do público-alvo da recolha de dados, egressos de todas as regiões do Brasil, principalmente no caso do questionário online. E justifica-se o uso da entrevista, por também ser um instrumento que pode ser utilizado com sujeitos de maiores distâncias através de recursos tecnológicos comunicacionais.

Porém, neste artigo serão apresentados apenas dados quantitativos colhidos no questionário. O questionário que foi utilizado na recolha de dados foi criado e aplicado na modalidade online na plataforma Googleforms, sendo disponibilizado na plataforma para o público de egressos oriundos de instituições de Ensino Superior das cinco regiões geográficas do Brasil, no período de 17/08/2017 a 10/09/2018. Foram direcionadas aos sujeitos 23 questões, distribuídas entre 07 (sete) questões abertas e 16 (dezesseis) fechadas, destas, 06 (seis) questões apresentaram a escala de Likert.

O questionário foi divulgado e seu link socializado em dois importantes espaços que ampliaram e possibilitaram a coleta nas 5 (cinco) regiões geográficas do país.

O primeiro espaço de maior impacto na divulgação foi no "V Workshop da Licenciatura em Computação (V WLIC)", ocorrido no "VI Congresso Brasileiro de Informática na Educação (CBIE 2017)", na cidade de Recife, Pernambuco, no período de 30 de outubro a 02 de novembro de 2017. Neste evento, foi possível divulgar o questionário entre docentes que atuam em cursos de LC de quatro regiões brasileiras (Nordeste, Centro-oeste, Sudeste e Sul).

O segundo espaço de divulgação do link do questionário online foi num grupo virtual no qual a autora é membro, trata-se de um grupo registrado no google groups, ${ }^{2}$ que tem como título "Fórum das Licenciaturas em Computação" no qual participam 37 (trinta e sete) professores e pesquisadores da área de Licenciatura em Computação de diversas instituições do país. Assim, responderam ao questionário 60 egressos, distribuídos nas cinco regiões geográficas do país conforme dados apresentados na Tabela 1.

\footnotetext{
${ }^{2}$ O google Groups trata-se de um ambiente virtual para criação de comunidades online e grupos de discussão, incluindo postagens da Usenet. Cada grupo criado tem seus administradores, para fazer parte do grupo é necessário ser convidado por um dos membros já participantes.
} 
VIII Congresso Brasileiro de Informática na Educação (CBIE 2019)

Anais do XXV Workshop de Informática na Escola (WIE 2019)

Tabela 1 Quantidade de Instituições de formação dos Licenciados em sujeitos que responderam ao questionário por região

\begin{tabular}{|c|c|c|}
\hline REGIÕES & INSTITUIÇÃO & $\begin{array}{l}\mathbf{N}^{0} \text { DE SUJEITOS QUE } \\
\text { FORAM INQUIRIDOS }\end{array}$ \\
\hline \multirow[b]{2}{*}{ Norte } & $\begin{array}{l}\text { Centro Universitário } \\
\text { Atual da Astácio } \\
\text { Roraima }\end{array}$ & 07 \\
\hline & \begin{tabular}{lrr} 
Instituto & \multicolumn{2}{c}{ Tocantinense } \\
Presidente & Antônio & Carlos \\
$($ ITPAC) & & \\
\end{tabular} & 01 \\
\hline \multirow[t]{6}{*}{ Nordeste } & $\begin{array}{l}\text { Instituto Federal de Educação, } \\
\text { Ciência e Tecnologia Baiano } \\
\text { (IFBaiano) }\end{array}$ & 04 \\
\hline & $\begin{array}{l}\text { Instituto Federal de Educação, } \\
\text { Ciência e Tecnologia da Bahia } \\
\text { (IFBA) }\end{array}$ & 06 \\
\hline & $\begin{array}{l}\text { Universidade Federal da Paraíba } \\
\text { (UFP) }\end{array}$ & 02 \\
\hline & $\begin{array}{lll}\begin{array}{l}\text { Universidade de } \\
\text { (UPE) }\end{array} & \text { Pernambuco } \\
\end{array}$ & 07 \\
\hline & $\begin{array}{l}\text { Universidade Federal Rural de } \\
\text { Pernambuco (UFRP) }\end{array}$ & 01 \\
\hline & $\begin{array}{l}\text { Universidade Estadual do Piauí } \\
\text { (UESPI) }\end{array}$ & 01 \\
\hline Centro Oeste & $\begin{array}{l}\text { Universidade Federal do Mato } \\
\text { Grosso }\end{array}$ & 10 \\
\hline Sudeste & $\begin{array}{l}\text { Instituto Federal do Triângulo } \\
\text { Mineiro (IFTM) }\end{array}$ & 09 \\
\hline \multirow[t]{2}{*}{ Sul } & $\begin{array}{l}\text { Instituto Federal Farroupilha (IF } \\
\text { Farroupilha }\end{array}$ & 07 \\
\hline & $\begin{array}{l}\text { Universidade de Santa Cruz do } \\
\text { Sul }\end{array}$ & 05 \\
\hline \multicolumn{2}{|c|}{ Total de pessoas } & 60 \\
\hline
\end{tabular}

Portanto, foram coletados 60 questionários válidos para essa pesquisa, relativos a uma população de 10.325 (dez mil trezentas e vinte e cinco) pessoas. Uma amostra não representa perfeitamente uma população. Ou seja, o uso de uma amostra supõe a aceitação de uma margem de erro, a qual se denomina erro amostral (Triola, 1999).

Para a realização do tratamento estatístico dos dados quantitativos do questionário online, foi utilizado o software livre RStudio.

\section{RESULTADOS E DISCUSSÃO}

Mediante a aplicação do questionário online foi possível verificar alguns aspectos que ajudam a construir o perfil dos sujeitos. 
VIII Congresso Brasileiro de Informática na Educação (CBIE 2019)

Anais do XXV Workshop de Informática na Escola (WIE 2019)

\section{Perfil dos sujeitos}

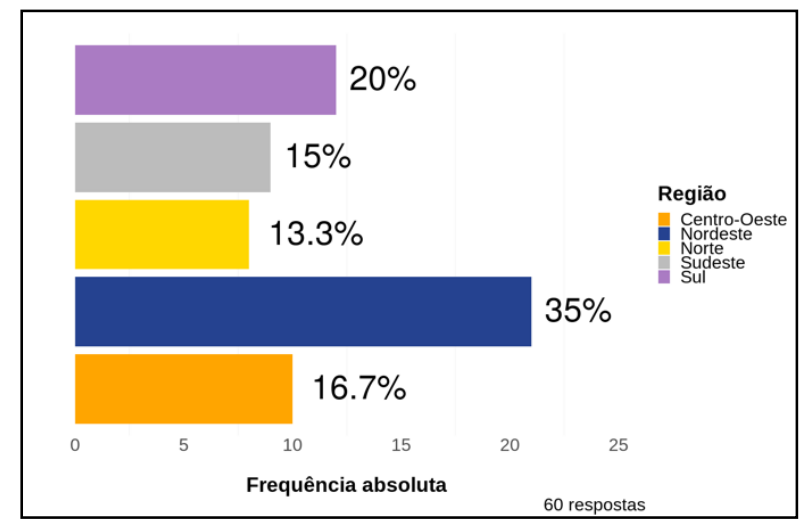

Figura 02 Distribuição dos sujeitos da pesquisa, de acordo com a localização geográfica de suas respectivas IES

Fonte: banco de dados do questionário online e criação do gráfico no software RStudio.

O maior índice de pessoas que responderam ao questionário foi de egressos da região Nordeste, este fato deve-se à aproximação da pesquisadora com instituições situadas nesta região e também à divulgação do questionário, quando do VI CBIE 2017, na cidade de Recife, Pernambuco, pois, embora seja um evento de abrangência nacional concentrou um percentual elevado de profissionais da região Nordeste.

É importante também conhecer-se a faixa etária em que se encontravam os egressos de LC, quando do preenchimento do questionário, pois a predominância de uma determinada faixa-etária pode, de certo modo, influenciar as respostas dos sujeitos. A faixa etária revela possíveis traços do ciclo de vida profissional destes sujeitos, conforme Huberman (2007).

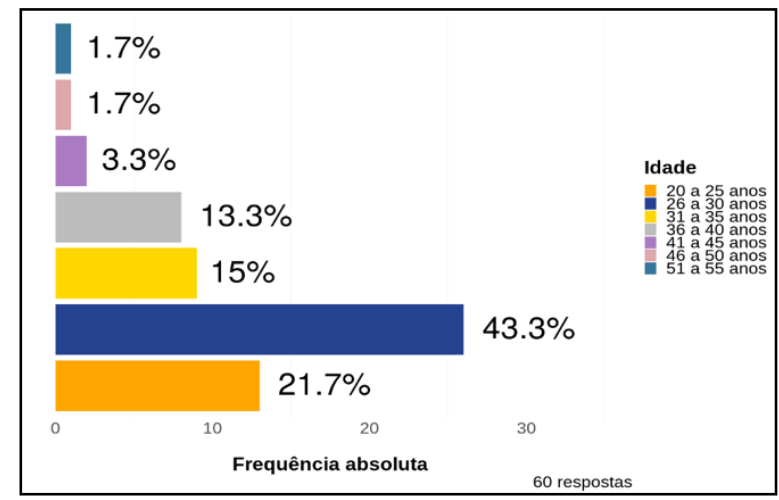

Figura 03 Faixa etária dos sujeitos da pesquisa

Fonte: banco de dados do questionário online e criação do gráfico no software RStudio.

Observa-se que há uma predominância na faixa etária entre 26 (vinte e seis) e 30 (trinta) anos e, em segundo lugar, aparece a faixa etária entre os 20 (vinte) e 25 (vinte e cinco). As duas faixas etárias juntas de 20 (vinte) a 30 (trinta) anos totaliza $65 \%$ dos 
VIII Congresso Brasileiro de Informática na Educação (CBIE 2019)

Anais do XXV Workshop de Informática na Escola (WIE 2019)

egressos que responderam ao questionário. Esse dado revela que a população de egressos ainda é relativamente jovem, visto que o tempo de duração e permanência no curso é em média de 4 (quatro) a 6 (seis) anos, postula-se que a maioria encontra-se em fase de início de carreira.

Quanto ao gênero, o que se pode observar é que na área da docência em Computação há uma disparidade na predominância de gênero se comparado à questão dessa categoria na atuação docente em outras áreas do conhecimento. Há nesse aspecto um certo distanciamento, já que a atividade docente, principalmente no que se refere ao ensino na Educação Básica, há predominância de pessoas de gênero feminino, porém, na área do ensino de Computação, o índice é inverso, há uma predominância de pessoas de gênero masculino.

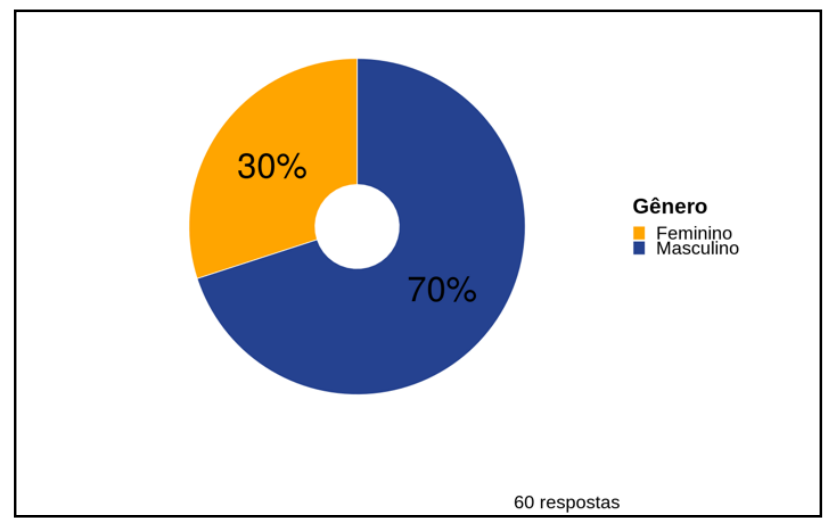

Figura 04 Percentual dos sujeitos da pesquisa, de acordo com o gênero

Fonte: banco de dados do questionário online de criação no software RStudio.

Esse dado reforça um aspecto inerente aos cursos da área de Computação. De acordo com Santos, Pereira e Abdalla Santos (2018), dados da Pesquisa Nacional de Amostra por Domicílios (PNAD) revelam que 79\% das mulheres que iniciam cursos superiores na área de Tecnologia da Informação abandonam o curso no primeiro ano, as autoras revelam que o ambiente acadêmico na área de Computação é considerado hostil e machista, desse modo, esse mesmo índice é refletido na amostra da pesquisa aqui apresentada.

\section{Inserção Profissional}

O curso de formação para professores de Computação é considerado recente no Brasil, se comparado aos demais cursos de formação de professores de outras áreas. Esse aspecto gera um clima de insegurança e de incertezas nos egressos que acabam por enfrentar as dificuldades de um curso que ainda não tem um campo de trabalho consolidado no que se refere à sua atuação na Educação Básica.

Todavia, também é uma formação que apresenta potencialidades e indicativos de exitosa inserção profissional para os egressos nos próximos anos, diante da emergência da inclusão mais efetiva das TDIC na educação e também devido ao surgimento de grandes demandas pela produção de recursos digitais educacionais em todas as áreas, sobretudo na escola. 
VIII Congresso Brasileiro de Informática na Educação (CBIE 2019)

Anais do XXV Workshop de Informática na Escola (WIE 2019)

A figura 05 apresenta o resultado da opinião dos 60 sujeitos inquiridos a respeito do grau de dificuldade da inserção profissional dos egressos de LC.

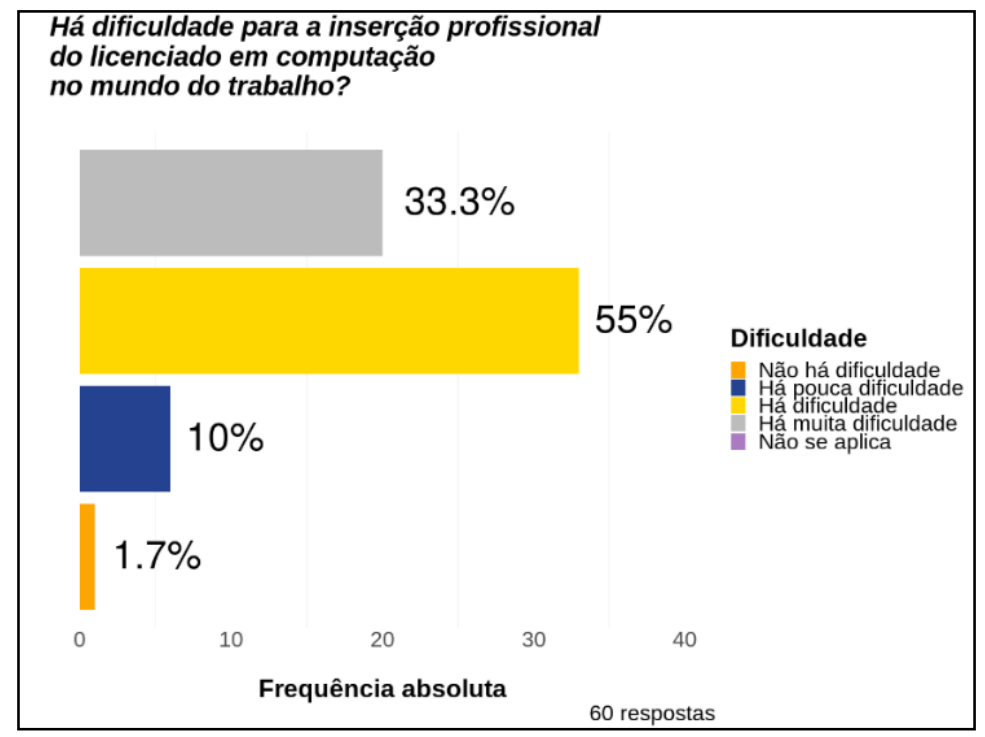

\section{Figura 05 Grau de dificuldade para a inserção profissional do licenciado em Computação}

Fonte: banco de dados do questionário online e criação do gráfico no software RStudio

Diante das respostas apresentadas, verifica-se que os egressos exprimem que há dificuldade em primeiro lugar, e em segundo lugar afirmam que há muita dificuldade na inserção profissional no mundo do trabalho, os dois aspectos juntos somam 88,3\%, apenas $11,7 \%$ afirmam que há pouca dificuldade e que não há dificuldade na inserção profissional do licenciado em Computação.

Há nos índices expostos na figura 22 grande expressividade dos egressos sobre a dificuldade de inserção profissional, esse fator deve-se à ausência de componente curricular específico na Educação Básica para a área de Computação.

É comum ser levantado um questionamento de viés mercadológico: por que formar um licenciado em Computação se não há disciplina obrigatória de Computação no ensino formal? [...] O fato é que a informática nas escolas existe, mas ainda é raro encontrar nelas o licenciado em Computação e tal situação precisa ser modificada (Castro \& Vilarim, 2013, p. 21).

No intuito de compreender mais claramente a inserção profissional do professor de computação os egressos também foram inquiridos sobre sua condição de atuação profissional quanto a atuação ou não no ensino de Computação no momento do preenchimento do questionário, obtendo-se o seguinte resultado apresentado na figura 06. 
VIII Congresso Brasileiro de Informática na Educação (CBIE 2019)

Anais do XXV Workshop de Informática na Escola (WIE 2019)

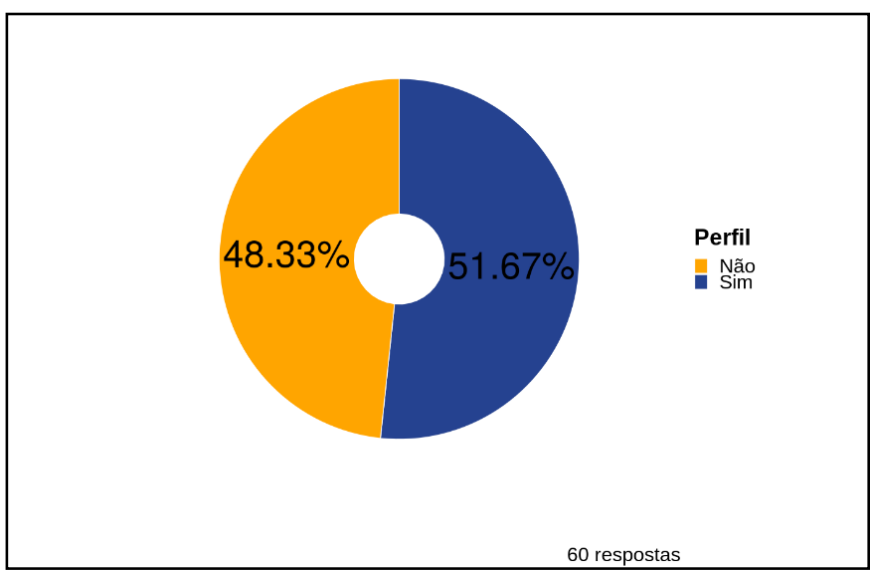

Figura 06 Percentual de egressos que atuam no ensino de Computação

Fonte: banco de dados do questionário online e criação do gráfico no software RStudio.

Com base no resultado apresentado na figura 06, denota-se que o índice de pessoas em atuação no ensino de Computação revela um quantitativo satisfatório e um indicador positivo para o êxito na inserção no mundo do trabalho. Diante do grau de dificuldade que foi apontado pelos próprios sujeitos no gráfico da figura 05 , percebe-se aqui uma aparente contradição nas respostas dos egressos, pois a realidade mostra que mais da metade dos sujeitos estão atuando no ensino e, em informações contidas em questões abertas deste mesmo questionário, dentre os 48,33\% que declararam que não estão atuando no ensino de Computação, grande parte destes declararam que estão a atuar em outras atividades ligadas ao domínio da área de tecnologias.

Desse modo, considerando-se o grau de dificuldade apontado pelos egressos na figura 05, a faixa etária desses sujeitos, ainda bastante jovens, e o fato de não haver oferta obrigatória do ensino de Computação na Educação Básica, o índice de 51,67\% que indica o grupo que está a atuar nessa área, apresenta-se como um dado positivo e que fortalece o desenvolvimento profissional desse egresso. E, por isso, tal dificuldade de inserção profissional pode estar particularmente relacionada e uma visão pragmática, pautadas muito mais numa concepção de mercado que de mundo do trabalho.

Porém, é válido ressaltar que a grande maioria que está a atuar no ensino de Computação não atua diretamente na Educação Básica regular. Os egressos estão trabalhando em cursos profissionalizantes, em cursos de Ensino Superior, em escolas de cursos técnicos de curta duração e em projetos interdisciplinares na Educação Básica. Apesar disso, a formação de professores para a área de Computação é ampla e proporciona a formação de um profissional que tem flexibilidade para dialogar com as demais áreas do currículo escolar.

A formação ampla e interdisciplinar na Licenciatura em Computação oferece subsídios pedagógicos, teóricos e empíricos para que o egresso, enquanto profissional, possa desenvolver competências específicas para sua atuação na escola, contribuindo eficazmente para o aprendizado técnico-crítico dos seus alunos e para a informática na educação como ferramenta de promoção da cidadania (Matos, 2013, p. 30). 
VIII Congresso Brasileiro de Informática na Educação (CBIE 2019)

Anais do XXV Workshop de Informática na Escola (WIE 2019)

\section{CONCLUSÃO}

Apesar de ser considerada uma formação inicial de professores ainda recente no Brasil, a base estatística desse estudo revelou que mais de $50 \%$ dos egressos estão a atuar no ensino de Computação em diversos espaços e segmentos educacionais. Dentre os demais egressos que não estão no ensino, a grande maioria está a trabalhar, porém, em espaços diferentes do ensino de Computação, mas relacionados a esse domínio.

Ressalta-se que os egressos avaliam a inserção profissional como um fator ainda desafiador, sob o aspecto da empregabilidade ${ }^{3}$ desse profissional no que se refere à atuação na Educação Básica. Porém, constatou-se que a profissão do licenciado em Computação apresenta qualidades potenciais para a inserção e atuação profissional. Em primeiro lugar, afirma-se que há uma expansão na oferta de cursos profissionalizantes na área de Computação no país, o que tem ampliado consideravelmente a promoção de vagas de trabalho para professores de Computação.

Considera-se uma potencialidade desta formação profissional a perspectiva de que licenciados qualificados (que possuem especialização ou outros cursos de pósgraduação) apresentam uma rápida e favorável inserção profissional.

Foram apresentados indicativos por parte dos egressos de Computação acerca da existência de uma demanda de oferta ainda não preenchida para a atuação docente em Computação na Rede Federal de Educação Tecnológica e em instituições de Ensino Superior. Há, em algumas regiões do país, situações nas quais os processos seletivos são abertos, mas não há um quantitativo suficiente de candidatos que possuam a formação em LC. A formação do licenciado em Computação lhe confere também possibilidades de atuação em diferentes espaços da educação formal, tais como a modalidade de Educação a Distância e a Educação de Atendimento Especializado.

\section{Referências}

Brasil. (2016)."Resolução CNE/CES n ${ }^{\circ}$ 05, de 16 de novembro de 2016. Institui as Diretrizes Curriculares Nacionais para os Cursos de Graduação em Computação". CNE/MEC. $\quad$ Brasília, 2016. Disponível em http://portal.mec.gov.br/index.php?option $=$ com_docman\&view $=$ download\&alias $=5210$ 1-rces005-16-pdf\&category_slug=novembro-2016-pdf\&Itemid=30192. Acesso em: 10 nov. 2017.

, Censo do Ensino superior 2016. (2017) INEP/MEC. Brasília. Disponível em http://download.inep.gov.br/educacao_superior/censo_superior/documentos/2016/censo _superior_tabelas.pdf. Acesso em: 10 nov. 2017.

\footnotetext{
${ }^{3} \mathrm{O}$ conceito de empregabilidade tem sido utilizado para referir-se às condições da integração dos sujeitos à realidade atual dos mercados de trabalho e ao poder que possuem de negociar sua própria capacidade de trabalho, considerando o que os empregadores definem por competência. (HELAL; ROCHA, 2011, p. 139)
} 
VIII Congresso Brasileiro de Informática na Educação (CBIE 2019)

Anais do XXV Workshop de Informática na Escola (WIE 2019)

Castro, C. S., Vilarim, G. O. (2013) Licenciatura em Computação no cenário nacional: embates, institucionalização e o nascimento de um novo curso. Revista Espaço Acadêmico. N. 148, p. 18-25. Setembro. Disponível em: http://periodicos.uem.br/ojs/index.php/EspacoAcademico. Acesso em: 08 fev. 2016.

Huberman, M. (2007) O ciclo de vida profissional dos professores. In: NÓVOA, A. (Org.), Vidas de professores. - Porto, Portugal: Editora Porto.

Jick, T. (1979) Mixing Qualitative and Quantitative Methods: triangulation in action. Administrative Science Quarterly, v. 24, n. 4, p. 602-611, dec., 1979. Disponível em: http://www.jstor.org/stable/2392366. Acesso em: 22 maio 2017.

Matos, E. S. (2013) Identidade profissional docente e o papel da interdisciplinaridade no currículo de licenciatura em computação. Revista Espaço Acadêmico. N. 148, p. 2634. Setembro.

Disponível em: http://periodicos.uem.br/ojs/index.php/EspacoAcademico> Acesso em: 18 fev. 2016.

Santos, J. M. O.; Pereira, K. A. S.; Abadalla Santos, D. (2017) O uso da programação para atração de mulheres à computação: relatos de experiência. Anais do XXXVII Congresso Brasileiro de Computação. São Paulo. Disponível em: http://portaldeconteudo.sbc.org.br/index.php/wit/article/view/3418/3380. Acesso em: ago. 2018.

Santos, W. O.; Hinterholtz L. T.; Silva, C. C. V.(2017) "Licenciatura em Computação: desafios e oportunidades na perspectiva do professor." In: Anais do VI Congresso Brasileiro de Informática na Educação (SBIE). XXIII Workshop de Informática na Escola. Disponível em: http://www.br-ie.org/pub/index.php/wie/article/view/7289 Acesso em: 12 set. 2018.

SBC, Educação Superior em Computação. (2017). "Estatísticas do Cursos de Computação 2016"!.Sociedade Brasileira de Computação. Porto Alegre, RS, 2017. Disponível em: http://www.sbc.org.br/documentos-da-sbc/summary/133-estatisticas/1007-estatisticasda-educacao-superior-2017 Acesso em: 27 mar. 2018.

Triola, M. F. (1999) Introdução à Estatística. $7^{\text {a }}$ Ed. - Rio de Janeiro:LTC. 